\title{
ЭФФЕКТИВНОСТЬ ПРИМЕНЕНИЯ ЛЕРКАНИДИПИНА У БОЛЬНЫХ АРТЕРИАЛЬНОЙ ГИПЕРТЕНЗИЕЙ
}

Вовк К. В., к. мед. н., дочент, медииинский факультет, кафедра общей практики-семейной медичины, Харьковский национальный университет имени В.Н. Каразина, Украина Николенко Е. Я., д. мед. н., профессор, медииинский факультет, кафедра общей практикисемейной медицины, Харьковский наџиональный университет имени В.Н. Каразина, Украина Власенко О. А., к.мед. н., дочент, медииинский факультет, кафедра общей практики-семейной медичины, Харьковский национальный университет имени В.Н. Каразина, Украина

Шумова Н. В., к. мед. н., доцент, медицинский факультет, кафедра общей практики-семейной медичины, Харьковский национальный университет имени В.Н. Каразина, Украина

Беляева Л. В., к. биол. н., доцент, медищинский факультет, кафедра общей практики-семейной медицинь, Харьковский национальньй университет имени В.Н. Каразина, Украина

Кратенко А. С., к.мед.н., дочент, медииинский факультет, кафедра общей практики-семейной медицины, Харьковский национальньй университет имени В.Н. Каразина, Украина

Николенко Е. $\boldsymbol{E}$., ассистент, медицинский факультет, кафедра общей практики-семейной медицины, Харьковский национальньй университет имени В.Н. Каразина, Украина

\section{DOI: https://doi.org/10.31435/rsglobal_conf/30012021/7389}

Abstract. Arterial hypertension (AH) remains one of the most pressing health problems, due to its high prevalence. With effective treatment of hypertension, the risk of cardiovascular complications and mortality are significantly reduced, that is, the main goal of the treatment of hypertension is achieved. European and Ukrainian recommendations for the diagnosis and treatment of hypertension distinguish five main classes of antihypertensive drugs: diuretics, $\beta$-blockers, calcium antagonists, angiotensin converting enzyme inhibitors and angiotensin receptor blockers. Based on the foregoing, we can conclude that the third-generation calcium antagonist lercanidipine is a highly effective, longacting antihypertensive drug for the treatment of hypertension of any stage and severity. It has organoprotective properties, is metabolically neutral, is well tolerated and can be successfully used both as monotherapy and in combination with any other (except dihydropyridine calcium antagonists) antihypertensive drugs in both men and women.

Keywords: Arterial hypertension, effective treatment, lercanidipine.

Введение. Артериальная гипертензия (АГ) остается одной из наиболее актуальных проблем здравоохранения, что обусловлено ее высокой распространенностью (в Украине АГ страдают около 46\% лиц старше 18 лет), способностью АГ вызывать поражение органовмишеней (сердце, почки, сосуды), и увеличивать частоту развития таких тяжелых осложнений, таких как как инфаркт миокарда, инсульт, хроническая сердечная недостаточность, ухудшение функции почек вплоть до развития терминальной почечной недостаточности. При эффективном лечении АГ достоверно снижается риск сердечно-сосудистых осложнений и смертность, то есть достигается основная цель лечения АГ. Европейские и Украинские рекомендации по диагностике и лечению АГ выделяют пять основных классов антигипертензивных препаратов: диуретики, bадреноблокаторы, антагонисты кальция, ингибиторы ангиотензинпревращающего фермента и блокаторы ангиотензиновых рецепторов [1, 2]. При выборе тактики ведения больного необходимо учитывать уровень АД, наличие и характер имеющихся факторов риска, органовмишеней, ассоциированных с АГ заболеваний (ишемическая болезнь, сахарный диабет, заболевания почек) и состояний. Разумеется, выбирая стратегию лечения $А Г$, следует учитывать опыт применения различных препаратов у пациента (как эффективность, так и переносимость). Другими словами, выбор препарата должен быть индивидуализирован $[3,4,5]$.

Дигидропиридиновые АК привлекательны доказанным органопротективным действием, включая кардио- и ангиопротективные эффекты, метаболической нейтральностью, минимумом противопоказаний, что делает их препаратами первого ряда, особенно у пациентов с ИСАГ, с сопутствующей ИБС, атеросклерозом сонных и коронарных артерий. К их несомненным достоинствам относится также сохранение эффективности при одновременном приеме нестероидных противовоспалительных препаратов. 
Для лечения АГ рекомендуется применять исключительно АК II-III поколений (пролонгированного действия), которые достоверно снижают риск развития сердечнососудистых осложнений, а по способности снизить риск инсульта даже являются лидерами среди прочих антигипертензивных препаратов (исследования ALLHAT, VALUE). При проведении метаанализа 13 крупных исследований (включавшего около 104 тыс пациентов с АГ) также было продемонстрировано достоверное снижение риска развития инсульта при терапии дигидропиридиновыми АК, причем это снижение не было напрямую связано с влиянием на уровень АД [6].

Наряду с амлодипином и лацидипином к антагонистам кальция (АК) III поколения относится препарат лерканидипин, обладающий рядом преимуществ перед прочими АК. Прежде всего следует подчеркнуть более высокую сосудистую селективность лерканидипина по сравнению с амлодипином, фелодипином, лацидипином [7] и его более высокую липофильность.

Основной раздел. Лерканидипин, как и другие АК дигидропиридинового ряда, обратимо связывается с кальциевыми каналами L-типа гладкомышечных клеток сосудов, что сопровождается вазодилатацией, снижением периферического сосудистого сопротивления и снижением АД без существенного повышения частоты сердечных сокращений (ЧСС). Благодаря высокой липофильности и, соответственно, высокому мембранному коэффициенту распределения (мембранная фармакокинетика), лерканидипин депонируется внутри двойного липидного слоя мембран гладкомышечных клеток сосудов. Способность лерканидипина накапливаться в мембране обеспечивают продолжительную блокаду кальциевых каналов при относительно недолгом периоде циркуляции препарата в крови (2-5 ч). В результате сосудорасширяющее и, соответственно, антигипертензивное действие препарата зависит именно от концентрации его в клеточной мембране, а не в плазме, как у других АК (с плазменной фармакокинетикой). Антигипертензивный эффект лерканидипина развивается постепенно и сохраняется длительно (коэффициент Т/Р превышает 83\%), что обеспечивает эффективность терапии при однократном применении препарата в сутки [7].

В исследовании ELYPSE изучали антигипертензивную эффективность лерканидипина в дозе 10 мг/сутки у 9059 пациентов с АГ I-II степени [8]. Уже через месяц отмечено снижение

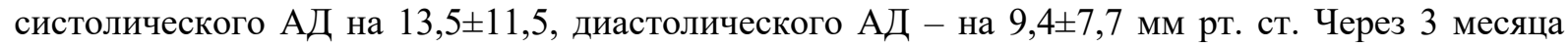
отмечено нарастание антигипертензивного эффекта и, что очень важно, незначительное, но достоверное $(\mathrm{p}<0,01)$ уменьшение ЧСС по сравнению с исходными показателями (как известно, увеличение ЧСС сопровождается увеличением риска сердечно-сосудистых осложнений).

У лиц с мягкой и умеренной АГ монотерапия лерканидипином в дозе 10 мг/сут на протяжении 4-х недель приводила к нормализации АД в 72-89\% случаев [9], увеличение дозы лерканидипина до 20 мг/сут достоверно усиливало его антигипертензивный эффект [10].

У больных с тяжелой АГ при назначении лерканидипина 20 мг/сут через месяц ежедневного приема препарата диастолическое АД снизилось на 22 мм рт. ст. У пожилых пациентов с ИСАГ применение лерканидипина в суточной дозе 10-20 мГ в течение 8 недель позволило достичь снижения систолического АД на 32 мм рт. ст. [11].

В многоцентровом рандомизированном исследовании COHORT сравнили эффективность и переносимость лерканидипина (в дозе 10-20 мг/сутки), амлодипина и лацидипина у 828 лиц старше 60 лет. Во всех трех группах достигнуто сопоставимое снижение АД - на 20/10 мм рт.ст. через 4 недели и на 30/14 мм рт.ст. - через 6 месяцев терапии [12]. Периферические отеки значительно чаще развивались в группе амлодипина (19\%) и чаще приводили к отмене препарата $(8,5 \%)$ по сравнению с лерканидипином (соответственно 9,0\% и 2,1\%). Частота других побочных эффектов в группах амлодипина и лерканидипина не отличалась.

В одном из исследований изучалась эффективность лерканидипина у женщин с мягкой и умеренной АГ в период постменопаузы: через 6 месяцев монотерапии АД нормализовалось у $49 \%$ женщин [13].

Выше уже упоминалось о более частом развитии у женщин по сравнению с мужчинами ГЛЖ. Поскольку ГЛЖ является прогностически неблагоприятным признаком в отношении риска развития ИМ и внезапной смерти, способности антигипертензивных препаратов вызывать ее регресс придается большое значение. Было показано, что по способности обеспечить регресс гипертрофии миокарда левого желудочка у лиц с АГ, лерканидипин превосходит блокатор 
рецепторов ангиотензина II лозартан и сопоставим с ингибитором АПФ эналаприлом $[14,15]$. Подобно другим АК, лерканидипин улучшает эндотелий-зависимую вазодилатацию, обладает антиатерогенным действием, несвязанным с его антигипертензивной активностью.

В отличие от большинства дигидропиридиновых антагонистов кальция, лерканидипин обладает также и нефропротективным действием. По данным M. Sabbatini и соавт. [16], лерканидипин расширяет не только приносящие, но и выносящие артериолы почечных клубочков, предупреждая тем самым повреждение гломерулярного аппарата у крыс со спонтанной гипертензией. По мнению авторов, именно с этим связано наличие у лерканидипина нефропротективного действия, которое было убедительно продемонстрировано в исследованиях DIAL и ZAFRA.

В рандомизированном двойном слепом контролируемом исследовании DIAL [17], в которое были включены 180 больных АГ, имеющих сахарный диабет 2 типа и персистирующую микроальбуминурию, было показано, что лерканидипин (10 мг/сутки) и рамиприл (5 мг/сутки) сопоставимы по способности снижать уровень экскреции альбумина. Лерканидипин вызывал значительное снижение уровня экскреции альбумина по сравнению с исходным уровнем, причем статистически значимых различий по сравнению с рамиприлом не отмечалось.

В исследование ZAFRA [18] были включены 175 пациентов с хронической почечной недостаточностью (ХПН) различной этиологии, получавшие ингибиторы АПФ или блокаторы рецепторов ангиотензина II, у которых, несмотря на это, сохранялось повышение АД и протеинурия. Через 6 месяцев после присоединения лерканидипина в дозе 10 мг в сутки увеличилось число больных с целевым уровнем АД, снизилась протеинурия, улучшилась функция почек. Таким образом, можно утверждать, что лерканидипин, благодаря своим уникальным нефропротективным свойствам, занимает особое место среди АК дигидропиридинового ряда в лечении диабетической нефропатии и недиабетических заболеваний почек, в том числе у пациентов с ХПН.

У больных пожилого возраста лерканидипин выглядит особенно привлекательным, поскольку, снижая АД, он улучшает мозговой кровоток [19]; в этом отношении лерканидипин подобен нимодипину, назначаемому неврологами при субарахноидальных кровоизлияниях. А по способности уменьшать отношение толщины стенки церебральной артерии к ее просвету, лерканидипин в экспериментальном исследовании на крысах со спонтанной гипертензией превзошел такие антигипертензивные препараты как гидралазин, манидипин, нимодипин [20]. Важна еще и очень хорошая переносимость лерканидипина у пожилых пациентов. Во всяком случае, частота побочных эффектов у пожилых $(5,4 \%)$ и более молодых пациентов $(6,6 \%)$ достоверно не отличалась [21].

Лерканидипин не ухудшает липидный и углеводный виды обмена, более того в исследовании M.Cafiero с соавт. [22] при назначении лерканидипина в дозе 10-20 мг 355 больным с умеренной АГ через 12 месяцев число больных с отклонением от нормы уровня глюкозы, общего холестерина и креатинина достоверно уменьшилось.

Известно, что при применении антигипертензивных препаратов у женщин чаще выявляются побочные эффекты. По данным исследования TOMHS (Treatment Of Mild Hypertension Study) [23], у женщин зарегистрировано в 2 раза больше нежелательных явлений, чем у мужчин. У женщин чаще развиваются гипокалиемия и гипонатриемия на фоне терапии диуретиками, сухой кашель на фоне приема ингибиторов АПФ, отеки голеней на фоне терапии антагонистами кальция. Отеки голеней нередко приводят к отказу женщин от продолжения терапии дигидропиридиновыми антагонистами кальция.

Хорошая переносимость лерканидипина была продемонстрирована в целом ряде исследований.

В иследовании C.Borghi с соавт. [24] перевод пациентов, получавших такие АК как амлодипин, нифедипин GITS и фелодипин, на терапию лерканидипином в дозе 10-20 мг/сутки привел к достоверному снижению частоты головных болей, приливов и отеков голеней через 4 недели терапии. При возврате к предыдущей терапии возвращались и ранее выявляемые побочные эффекты, что, несомненно, свидетельствует о лучшей переносимости лерканидипина по сравнению с вышеперечисленными АК. Лерканидипин хорошо переносился и в вышеупомянутом исследовании M.Cafiero с соавт. [25.]. Только у 5,6\% больных препарат был отменен из-за развития 
побочных эффектов. Через 12 месяцев приверженность к проводимой терапии составила более 80\%. И, наконец, в упоминавшемся ранее исследовании Elypse [8] отмечено уменьшение частоты побочных эффектов через 3 месяца от начала терапии лерканидипином.

По данным метаанализа 20 клинических плацебо-контролируемых исследований, включавших около 1800 больных АГ, нежелательные явления встречались у 11,8\% больных, получавших лерканидипин (10-20 мг/сутки, $\mathrm{n}=1317)$, и у 7\% больных на плацебо (n=227). Доля больных, отказавшихся от продолжения терапии, в обеих группах не отличалась. Причем, если лечение лерканидипином сразу начинали с дозы 20 мг, частота побочных эффектов оказывалась выше, а если стартовой дозой была доза 10 мг, но позже дозу увеличивали до 20 мг, побочные эффекты регистрировались значительно ниже.

Прекрасная переносимость лерканидипина в суточной дозе 10 мг была отмечена в многоцентровом 6-недельном исследовании, включавшем 32345 больных мягкой и умеренной АГ с сопутствующими ИБС, сахарным диабетом, хронической сердечной недостаточностью и дислипидемией. По завершении исследования была отмечена крайне низкая частота развития побочных реакций (покраснение лица $-0,3 \%$, периферические отеки $-0,14 \%$, сердцебиение $-0,06 \%$ [26].

Поскольку женщины в постменопаузальном периоде особенно подвержены развитию отеков голеней и стоп (нередко являющихся причиной отказа от приема антагонистов кальция), интересны результаты исследования R.Fogari с соавт. [27]. Авторы в своем исследовании использовали известный закон: тело, погруженное в воду, вытесняет объем жидкости, равный объему погруженного тела, то есть был исключен субъективизм в оценке выраженности претибиальных отеков. Оказалось, что при погружении в воду ног больных, получавших лерканидипин, объем вытесненной воды гораздо меньше по сравнению с больными, получавшими нифедипин GITS. В исследовании P.Lund-Johansen с соавт. [28] были получены сходные результаты: объем нижних конечностей на лерканидипине изменился в гораздо меньшей степени по сравнению с амлодипином; достоверно реже выявлялись отеки голеней и стоп $(9,8 \%$ против $33,3 \%)$. В результате в группе амлодипина частота отмены препарата из-за развития отеков составила $6,8 \%$, в то время как в группе лерканидипина не было зарегистрировано ни одного такого случая.

Лерканидипин хорошо себя зарекомендовал и в составе комбинированной терапии. При недостаточной эффективности атенолола, эналаприла или комбинации гидрохлоротиазида с амилоридом, назначение в дополнение к этим препаратам лерканидипина в дозе 10 мг/сут уже через 4 недели позволило достичь целевого уровня диастолического АД у 76\% больных. Через 12 недель число больных, достигших целевого уровня диастолического АД, увеличилось до $92 \%$ [29]. Лерканидипин может быть добавлен к любому другому антигипертензивному препарату с целью добиться усиления эффекта. Есть основания считать очень хорошей комбинацию лерканидипина с ингибиторами АПФ, так как в этом случае помимо повышения эффективности антигипертензивной терапии можно рассчитывать на взаимное уменьшение выраженности возможных нежелательных эффектов. Лерканидипин способен уменьшить выраженность сухого кашля благодаря снижению гиперреактивности бронхов, а ингибитор АПФ, в свою очередь, уменьшить отеки стоп и голеней, которые потенциально могут появляться при использовании любого антагониста кальция из-за присущего им артериолярного вазодилатирующего эффекта, возникающего (за счет расширения посткапиллярных венул, приводящего к снижению гидростатического давления в капиллярах. За рубежом уже несколько лет с успехом применяется официнальная комбинация лерканидипина и эналаприла.

В Австралии страховыми компаниями была ретроспективно изучена общая смертность среди больных АГ, получавших дигидропиридиновые АК (амлодипин, фелодипин, нифедипин и лерканидипин) в виде моно- или комбинированной терапии [30]. Через 4 года общая смертность в группах нифедипина, амлодипина и фелодипина оказалась значительно выше по сравнению с лерканидипином. Следует отметить, что больные, получавшие лерканидипин, значительно реже отказывались от продолжения терапии. Одной из возможных причин лучшего влияния лерканидипина на прогноз может быть влияние на центральное пульсовое давление. S. Isla. с соавт. при назначении в течение 10 недель пациентам старше 60 лет с изолированной систолической АГ периндоприла, атенолола, лерканидипина или тиазидного 
диуретика бендрофлуазида, обнаружили снижение центрального пульсового давления в группе периндоприла, лерканидипина и диуретика, в то время как атенолол на центральное пульсовое давление влияния не оказывал. Лерканидипин также снижал индекс аугментации (снижение индекса означает уменьшение жесткости аорты), в то время как атенолол его повышал [31].

Выводы. На основании вышесказанного можно сделать вывод, что антагонист кальция третьего поколения лерканидипин является высокоэффективным, длительно действующим антигипертензивным препаратом для лечения АГ любой стадии и степени тяжести. Он обладает органопротекторными свойствами, метаболически нейтрален, прекрасно переносится и может успешно применяться как в качестве монотерапии, так и в комбинации с любыми другими (кроме дигидропиридиновых антагонистов кальция) антигипертензивными препаратами как у мужчин, так и у женщин. А поскольку леркаменидипин не только эффективно снижает АД, но и обладает лучшей среди всех антагонистов кальция дигидропиридинового ряда переносимостью и удобен в применении (соответствие девизу «Один день - одна таблетка»), при его назначении есть основания рассчитывать на более высокий уровень приверженности пациентов к назначенной терапии.

\section{ЛИТЕРАТУРА}

1. Williams B., Mancia G., Spiering W. et al.; ESC Scientific Document Group (2018) 2018 ESC/ESH Guidelines for the management of arterial hypertension. Eur. Heart J., 39(33): 3021-3104.

2. Burt V.I., Whelton P., Prevalence of hypertension in the US adult population. Results from the Third National Health and Nutrition Examination Survey, 1988-1991.NHANES III Hypertension. 1995; 25 (3): 305-13.

3. Wassertheil-Smoller S., Anderson G., Psaty B.M. et al. Hypertension and its treatment in postmenopausal women: baseline data from the Women's Health Initiative. Hypertension. 2000; 36: 780-789.

4. Оганов Р.Г. Гендерные различия кардиоваскулярной патологии. Кардиоваскулярная терапия и профилактика. 2012. 11 (4): 101-104.

5. Coca A. (2018) Summary of what's new in this hypertension guideline and gaps in the evidence (https://esc365.escardio.org/Congress/ESC-Congress-2018/2018-ESC-ESH-Guidelines-on-ArterialHypertension/172123-summary-of-what-s-new-in-this-hypertension-guideline-and-gaps-in-the-evidence).

6. Angeli F. et al. Calcium channel blockade to prevent stroke in hypertension: a meta-analysis of 13 studies with 103,793 subjects. Am J Hypertens. 2004 Sep; 17 (9): 817-22.

7. Angelico P., Guarneri L., Leonardi A. et al. Vascular-selective effect of lercanidipine and other 1,4dihydropyridines in isolated rabbit tissues. J. Pharmacol. 1999; 51: 709-714.

8. Barrios V., Navarro A., Esteras A. et al. Antihypertensive efficacy and tolerability of lercanidipine in daily clinical practice. The ELYPSE study. Blood Press. 2002; 11 (2): 95-100.

9. Bang L.M., Chapman T.M., Goa K.L. Lercanidipine: a review of its efficacy in the management of hypertension. Drugs. 2003; 63: 2449-72.

10. Paterna S., Licata A., Arnone S. et al. Lercanidipine in two different dosage regimens as a sole treatment for severe essential hypertension. J. Cardiovasc. Pharmacol. 1997; 29: Suppl. 2: S50-53.

11. Barbagallo M., Barbagallo S.G. Efficacy and tolerability of lercanidipine in monotherapy in elderly patients with isolated systolic hypertension. Aging Clin. Exp. Res. 2000; 12: 5: 375-379.

12. Zanchetti A. Emerging data on calcium-channel blockers: the COHORT study. Clin Cardiol. 2003; 26: Suppl. 2: 17-20.

13. Herrera J., Ghais Z., Gonzalez L. Antihypertensive treatment with a calcium channel blocker in postmenopausal women: prospective study in a primary health care setting [abstract no. P0680]. J Hypertens. 2002; 20: Suppl. 4: S162.

14. Fogari R., Mugellini A., Corradi L. et al. Efficacy of lercanidipine vs losartan on left ventricular hypertrophy in hypertensive type 2 diabetic patients [abstract No. P1.191]. J. Hypertens. 2000; 18: Suppl. 2: S65.

15. Sanchez A., Sayans R., Alvarez J.L. et al. Left ventricular hypertrophy regression after a short antihypertensive treatment with lercanidipine vs. enalapril [abstract no. 12]. // Fourth European Meeting on Calcium Antagonists; 1999; Oct 27-29; Amsterdam.

16. Sabbatini M., Leonardi A., Testa R. et al. Effect of calcium antagonists on glomerular arteriolesin spontaneously hypertensive rats. Hypertension. 2000; 35 (3): 775-9.

17. Dalla Vestra M., Pozza G., Mosca A. et al. Effect of lercanidipine compared with ramipril on albumin excretion rate in hypertensive Type 2 diabetic patients with microalbuminuria: DIAL study (diabete, ipertensione, albuminuria, lercanidipina). Diabetes Nutr Metab. 2004; 17 (5): 259-66.

18. Robles N.R., Ocon J., Gomez C.F. et al. Lercanidipine in Patients with Chronic Renal Failure: The ZAFRA study. Ren Fail. 2005; 27 (1): 73-80.

19. Sironi G., Colombo D., Greto L et al. Regional vasodilating effects of lercanipine in dogs. ISHR XVI World Congress, 1998. 
20. Sabbatini M., Tomassoni D., Amenta F. Influence of treatment with $\mathrm{Ca}^{+}{ }^{+}$antagonistis on cerebral vasculature of spontaneously hypertensive rats. Mechanisms of Ageing and Development. 2001; 122: 795-809.

21. Leonetti G. The safety profile of antihypertensive drugs as the key factor for the achievement of blood pressure control: current experience with lercanidipine. High Blood Press. 8:92-101.

22. Cafiero M., Giasi M. Long-term (12-month) treatment with lercanidipine in patients with mild to moderate hypertension. J Cardiovasc Pharmacol. 1997; 29: Suppl 2: S45-49.

23. Grimm R.H., Grandits G.A., Cutler J.A. et al. Relationships of quality-of-life measures to long-term lifestyle and drug treatment in the Treatment of Mild Hypertension Study (TOMHS). Arch Intern Med. 1997; 157 (6): :638-48.

24. Borghi C., Prandin M.G., Dormi A. The use of lercanidipine can improve the individual tolerability to dihydropyridine calcium blockers in hypertensive patients [abstract]. J Hypertens. 2000; 18: Suppl 2: S155.

25. Cafiero M., Giasi M. Long-term (12-month) treatment with lercanidipine in patients with mild to moderate hypertension. J Cardiovasc Pharmacol. 1997; 29: Suppl 2: S45-49.

26. Marx A., Lichtenthal A., Milbredt C. et al. Effect of anthypertensive therapy with a new third generation calcium antagonist lercanidipine on patients with concomitant diseases. J Hypertens. 2004; 22: Suppl 2: S236.

27. Fogari R., Malamani G.D., Zoppi A. et al. Comparative effect of lercanidipine and nifedipine gastrointestinal therapeutic system on ankle volume and subcutaneous interstitial pressure in hypertensive patients: a double-blind, randomized, parallel-group study. Curr Ther Res. 2000; 61 (12): 850-62.

28. Lund-Johansen P., Stranden E., Helberg S. et al. Quantification of leg oedema in postmenopausal hypertensive patients treated with lercanidipine or amlodipine. J. Hypertens. 2003; 21: 1003-1010.

29. Rengo F., Romis L. Activity of lercanidipine in double-blind comparison with nitrendipine in combination treatment of resistant essential hypertension. J. Cardiovasc. Pharmacol. 1997; 29: Suppl. 2: S54-58.

30. Ortiz M., Calcino G. Inferred Mortality Differences between Dihydropyridine Antihypertensives. Hypertension. 2009; 53: 1116.

31. Mackenzie I.S., McEniery C.M. et al. Comparison of the Effects of Antihypertension Agents on Central Blood pressure and Arterial Stiffness in Isilated Systolic Hypertension. Hypertension. 2009; 54: 409-413. 